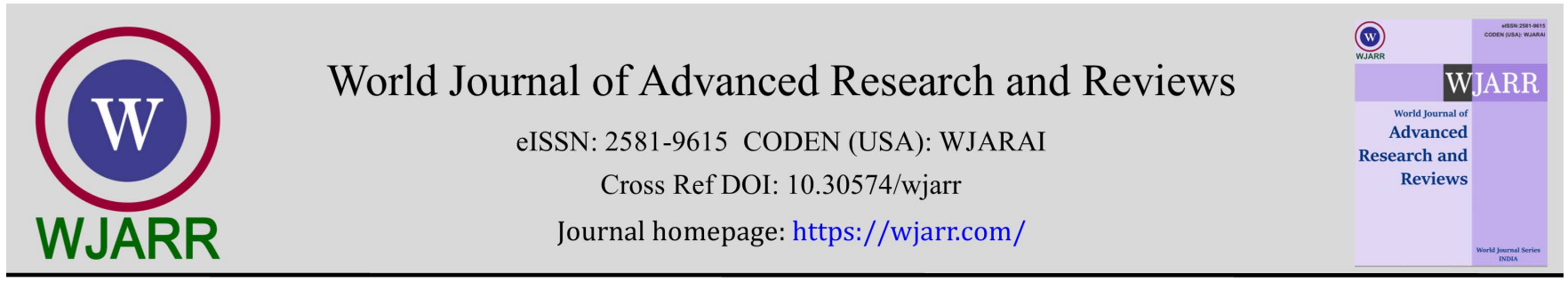

(CASE REPORT)

Check for updates

\title{
Advancing Age in Africa, the Urgent Need for Institutional Geriatric Care in a Low Resource Setting: A Case Report
}

\author{
Emmanuel Kobina Mesi Edzie 1, 2, , Klenam Dzefi-Tettey 3, Philip Narteh Gorleku 1, Frank Naku Ghartey 4 , \\ Madison Adanusa 5, Frank Quarshie 6, Bernard Osei 6, Henry Kusodzi ${ }^{1}$ and Abdul Raman Asemah ${ }^{1}$ \\ ${ }^{1}$ Department of Medical Imaging, School of Medical Sciences, College of Health and Allied Sciences, University of Cape \\ Coast, Cape Coast, Ghana. \\ 2 Department of Radiology, Cape Coast Teaching Hospital, Cape Coast, Ghana. \\ ${ }^{3}$ Department of Radiology, Korle Bu Teaching Hospital, 1 Guggisberg Avenue, Accra, Ghana. \\ ${ }^{4}$ Department of Chemical Pathology, School of Medical Sciences, College of Health and Allied Sciences, University of Cape \\ Coast, Cape Coast, Ghana. \\ ${ }^{5}$ Department of Family Medicine, Geriatric Unit, University of Cape Coast Hospital, Cape Coast, Ghana. \\ ${ }^{6}$ African Institute for Mathematical Sciences (AIMS), Summerhill Estates, East Legon Hills, Santoe, Accra, Ghana.
}

World Journal of Advanced Research and Reviews, 2021, 12(02), 416-420

Publication history: Received on 13 October 2021; revised on 17 November 2021; accepted on 19 November 2021

Article DOI: https://doi.org/10.30574/wjarr.2021.12.2.0610

\begin{abstract}
Background: The demand for geriatric care has been on the increase throughout the world, especially in the developing, low- and middle-income countries (LMICs), due to increasing life expectancy, improvement in technology in healthcare industry coupled with increasing numbers of healthcare personnel. Nonetheless, these increases in the resources to the healthcare industry are still woefully inadequate in the developing and LMICs, compared to the high demand for such services, thereby exposing the drastic challenges and gaps in geriatric services in these countries.
\end{abstract}

Case Presentation: A 74-year-old woman apparently well, who was relocated from the rural area by her biological daughter, with the intention of giving her better care in a comfortable city environment. She was initially appreciative of the relocation. However, the situation went sour when her daughter and son-in-law resumed work after their annual leave period. They started locking her up in a well-furnished mansion with everything she may need until they returned from work. Consistently for eight working days, she was kept under lock and key because they did not want her to roam around the community, they thought was not familiar to her with the intention of keeping her safe. Everything was fine until they returned from work one day to find that she had soiled the house with her excrement, apparently as a protest against her consistent lock-up. This necessitated their visit to the hospital. A diagnosis of social isolation was made after clinical and mental state examination and appropriate interventions were instituted. The patient consequently became fine in the new environment.

Conclusion: This case has been presented in order to emphasize the need to improve the systems for geriatric care which is of public health concern, especially as the life expectancy of the developing, low- and middle-income countries keep improving.

Keywords: Advancing age; Geriatric care; Ghana; Low-resource setting; Africa

\footnotetext{
${ }^{*}$ Corresponding author: Emmanuel Kobina Mesi Edzie

Department of Medical Imaging, School of Medical Sciences, College of Health and Allied Sciences, University of Cape Coast, Cape Coast, Ghana.

Copyright $(2021$ Author(s) retain the copyright of this article. This article is published under the terms of the Creative Commons Attribution Liscense 4.0.
} 


\section{Introduction}

Aging is a gradual, continuous process of natural change with time, that is characterized by impaired function and surged vulnerability to death resulting from gradual loss of physiological integrity [1]. A report from the world health organization in 2021 showed that, populations worldwide are aging at a faster rate than in previous years, and this demographic change, will have an effect on almost all aspects of life [2]. The report also disclosed that, most of the one billion people $\geq 60$ years are in LMICs, the majority of which are African countries. This tends to pose threats to the quality of life and creates multiple barriers that hinder their full involvement in society, as the basic resources needed for a meaningful life, are inaccessible to most of them in those countries including Ghana [2, 3]. We therefore report on this aged patient with geriatric care issues in a low resource setting.

\section{Case Report}

We present a case of a 74-year-old woman belonging to a working-class family, living in a city in Ghana, who was brought to the consulting room of a general practitioner in a tertiary facility. The patient had been apparently well, hearty and full of energy in the rural community in Ghana until she was relocated to live with her biological daughter, in order for her to be catered for by her daughter because she was living alone in the village. Her daughter then brought her home to live with her and the husband at the time when they were both on leave from their work. The elderly woman initially felt very happy and appreciative of the relocation because she got access to good quality general healthcare and the warmth of living with her only daughter. The situation however went sour when her daughter and son-in-law resumed work as they started locking her up in a well-furnished mansion with everything she may need until they returned from work since there are very few care homes currently in our setting. Consistently for eight working days, she was kept under lock and key because they did not want her to roam around the community, they thought was not familiar to her with the intention of keeping her safe.

Everything was fine until they returned from work one day to find that she had soiled the house with her excrement; from the living room, kitchen, bedrooms and study-room and was quietly seated in their living room. This necessitated their visit to the hospital. After a thorough history and clinical examination, including a mental state examination, everything was normal. Her blood pressure was $128 / 73 \mathrm{mmHg}$, pulse 84 beats per minutes and her mood was normal. Further inquiry revealed that, the actions of the patient were in protest against the constant lock up she was subjected to, hence a diagnosis of social isolation was made. The family was counseled and encouraged to employ a caregiver for her. This was done and everything returned to normal afterwards. We report this case in order to emphasize the need to improve the systems for geriatric care especially as the life expectancy of the developing, low- and middle-income countries keep improving.

\section{Discussion}

Rapid aging is a global phenomenon that poses economic, social, and healthcare consequences, particularly in the lowand middle-income countries [4]. A data-backed projection by the United Nations estimates that, the total number of older persons (60 years and older) will double to reach nearly 2.1 billion by 2050 and $80 \%$ will be from the low- and middle-income countries [5, 6]. Despite the surge in numbers of elderly people and the increase in the burden of chronic diseases among the aged, a recent study by Dotchin et al., revealed that, there are few geriatricians in Africa, due to no formal undergraduate/ postgraduate training for medical students in geriatrics [7]. In Uganda, a study by Ssensamba et al., showed a low preparedness of public health facilities to offer geriatric cordial care services due to gaps in the healthcare systems, thereby calling for healthcare reforms to sufficiently cater for service provision for the aged in Uganda [8].

The demand for geriatric care has been on the increase throughout the world, especially in the developing, low- and middle-income countries, due to increasing life expectancy and improvement in technology in healthcare industry [9, 10]. Studies in Ghana have also reported a tandem-like increase in the aged population with the global pattern [11, 12]. Results from the 2021 population and housing census in Ghana showed an increase in Ghana's population, but at a decreased rate. According to the Ghana Statistical Service, the de facto population of Ghana in 2021 is estimated to be 30.8 million with a proportion of $7.2 \%$ constituting the aged ( $\geq 60$ years) reported from previous estimation, which is higher as compared to the 4.9\% recorded in 1960 [13-15]. This figure for the aged (2.23 million) has been projected to double in less than 30 years [5].

A study by Fong in 2019 revealed that, about $80 \%$ of the aged, have at least one chronic disease [16]. Common diseases associated with old age include diabetes, coronary artery disease, hypertension, depression, and anemia. Dementia, 
urinary incontinence, mobility issues, hearing loss and falls are some other geriatric-specific conditions, which without proper geriatric care, would result in the deterioration of the health of the aged, but in our case report, the patient was physically well [17-19]. In Ghana, most families provide support to their aging relatives, but this care and time-honored respect for the aged is fast abrading, due to migration of the youth, who are mostly expected to take care of the aged in a typical Ghanaian extended family system, and also due to increasing urbanization, desire to pursue higher academic laurels and the stressful work demand in urban areas $[11,20]$.

In Nigeria, a study by Amare et al., has also highlighted a rapid urbanization of the youth in the country and Sub-Saharan Africa. The reason for this finding was ascribed to the inability to accelerate economic growth in rural communities, in the form of creating jobs in those areas and the unbalanced growth between the urban and rural areas, resulting in migration even outside the country [21]. A report from the United Nations has shown that, about 27 million young people migrate from their country of birth in search of employment abroad, associating the key drivers of migration to the aforementioned reasons together with other drivers like marriage, environmental change, and escape from conflict, violence and poverty [22].

Despite the positive impact of youth migration, thus exposure to opportunities, it has also reduced their support in catering for the aged in Africa, thereby increasing the burden of the aged, especially in this era where there are limited or no geriatric facilities in most African countries coupled with weak institutional support [23]. In Cameroon, a study by Nangia reported on the dire need of assistance and the persistent difficulties faced by the elderly due to poverty and weak institutional support. The study also highlighted the unavailability of any specific legislation for the promotion and protection of the rights of the elderly in the country [24]. A recent study in Togo also showed that, there are no dedicated geriatric wards available in the country, which is also the case for most African countries [25].

In Ghana, there are no public residential aged care facilities, but there are few private ones that offer a wide range of services consisting of care out of home and care in usual dwelling units. The elderly care out of home also consists of residential and non-residential aged care facilities, where both trained and untrained caregivers as support staffs, offer services for the elderly [26]. Notwithstanding, services rendered by these private facilities are skewed towards the rich, as the average aged Ghanaian family could not afford their services, hence the need to have some public facilities to bridge this gap, which has clearly been highlighted in this case report, emphasizing the need for systemic institutions for geriatric services. Even though the government of Ghana through the ministry of employment and social welfare, has enacted the National Aging Bill, to ensure complete exemption of those $\geq 70$ years from paying the basic healthcare premium of the National Health Insurance Scheme, a study has reported on the low impact of this policy due to the exclusion of those 60-69 years, hence the need to include them to ensure free access to basic healthcare for all the aged [27].

Fortunately, our patient was relatively well, as her general health status (pulse, blood pressure, and mental state) was unremarkable, except the presence of physical isolation. In other studies, the pulses of the patients were also normal but they presented with other conditions ranging from mild to severe, causing them to be at risk of experiencing adverse drug events, thereby needing necessary attention so as to optimize healthcare for the aged [28-30]. We believe, if our patient had benefited from institutionalized professional geriatric care, she would have integrated and enjoyed her new environment well intended for, by her family.

\section{Implication for Practice}

The unavailability and inadequacy of geriatric institutions and services in this era of increasing life expectancy in lowand middle-income countries, is a time-bomb, which needs urgent and focused attention as it is of a public health concern.

\section{Conclusion}

Increasingly, humans are living longer on earth, despite the numerous health challenges like the physical, psycho-social and spiritual disorders. This is mainly due to advancement in healthcare technology and improvement in institutional healthcare delivery. This situation would ultimately result in myriads of geriatric challenges, impacting on the existing institutional capacities and even overwhelming these institutions, in many low- and middle-income countries. This case has been presented in order to emphasize the need to improve the systems for geriatric care especially as the life expectancy of the developing, low- and middle-income countries keep improving. 


\section{Compliance with ethical standards}

\section{Acknowledgments}

The authors are appreciative of the family for giving us the consent for this paper to be written for publication.

\section{Disclosure of conflict of interest}

The authors declare that they have no competing interests.

\section{Statement of ethical approval}

Ethical approval was not required for this study but consent to participate was obtained.

\section{Statement of informed consent}

Informed consent was obtained from the elderly woman and her family for this case to be reported for publication.

\section{Authors' Contributions}

Emmanuel Kobina Mesi Edzie, Klenam Dzefi-Tettey, Philip Narteh Gorleku, Frank Naku Ghartey and Madison Adanusa substantially contributed to conception and design, or acquisition of data, or analysis and interpretation of data; and final approval of the version to be published. Frank Quarshie, Bernard Osei, Henry Kusodzi and Abdul Raman Asemah contributed in the data collection, writing of the case, drafting the article or revising it critically for important intellectual content; and final approval of the version to be published.

\section{References}

[1] López-Otín C, Blasco MA, Partridge L, Serrano M, Kroemer G. The hallmarks of aging. Cell. 2013; 153(6): 1194 217.

[2] World Health Organization (WHO). UN Decade of Healthy Ageing 2021-2030. 2021.

[3] Longev LH. Care for ageing populations globally. Lancet. 2021; 4(2).

[4] Ogura S, Jakovljevic MM. Global population aging-health care, social and economic consequences. Front Public Health. 2018; 6: 335.

[5] United Nations (UN). Department of Economic and Social Affairs. Population Division. World Population Ageing 2017.

[6] Edzie EKM, Gorleku PN, Dzefi-Tettey K, Idun EA, Amankwa AT, Aidoo E, Asemah AR, Kusodzi H. Incidence rate and age of onset of first stroke from CT scan examinations in Cape Coast metropolis. Heliyon. 2021 Feb 1;7(2):e06214.

[7] Dotchin CL, Akinyemi RO, Gray WK, Walker RW. Geriatric medicine: services and training in Africa. Age Ageing. 2013; 42(1): 124-8.

[8] Ssensamba JT, Mukuru M, Nakafeero M, Ssenyonga R, Kiwanuka SN. Health systems readiness to provide geriatric friendly care services in Uganda: a cross-sectional study. BMC Geriatr. 2019; 19(1): 1-3.

[9] Wamble DE, Ciarametaro M, Dubois R. The effect of medical technology innovations on patient outcomes, 19902015: results of a physician survey. J Manag Care Spec Pharm. 2019; 25(1): 66-71.

[10] African Development Bank-Chief Economist Complex. Health in Africa over the next 50 Years. 2013.

[11] Essuman A, Gold KJ, Vitale C, et al. A Collaboration Between the University of Michigan and the Ghana College of Physicians and Surgeons. Establishing the first geriatric medicine fellowship program in Ghana. J Am Geriatr Soc. 2019; 67(8): 1718-23.

[12] Kpessa-Whyte M, Tsekpo K. Lived experiences of the elderly in Ghana: Analysis of ageing policies and options for reform. J Cross Cult Gerontol. 2020; 35: 341-52.

[13] Ghana Statistical Services. Statistics Infobank. Press Release on 2021 Provisional Results. 2021.

[14] Ghana Statistical Service. Social and Demography. 2020. 
[15] Tawiah EO. Population ageing in Ghana: a profile and emerging issues. Afr Popul Stud. 2011; 25(2).

[16] Fong JH. Disability incidence and functional decline among older adults with major chronic diseases. BMC Geriatr. 2019; 19(1): 1-9.

[17] Jaul E, Barron J. Age-related diseases and clinical and public health implications for the 85 years old and over population. Front Public Health. 2017; 5: 335.

[18] Nwani PO, Isah AO. Chronic diseases and multimorbidity among elderly patients admitted in the medical wards of a Nigerian tertiary hospital. J Clin Gerontol Geriatr. 2016; 7(3): 83-6.

[19] Mugisha JO, Schatz EJ, Randell M, et al. Chronic disease, risk factors and disability in adults aged 50 and above living with and without HIV: findings from the Wellbeing of Older People Study in Uganda. Glob. Health Action. 2016; 9(1): 31098.

[20] Agyemang FA. Survival strategies of the elderly in rural Ghana. 2021.

[21] Amare M, Abay KA, Arndt C, Shiferaw B. Youth Migration Decisions in Sub-Saharan Africa: Satellite-Based Empirical Evidence from Nigeria. Popul Dev Rev. 2021; 47(1): 151-79.

[22] United Nations (UN), Department of Economic and Social Affairs. Youth and Migration. 2016.

[23] Akoria OA. Establishing in-hospital geriatrics services in Africa: Insights from the University of Benin Teaching Hospital geriatrics project. Ann Afr Med. 2016; 15(3): 145.

[24] Nangia EN. Care for older persons in Cameroon: Alternatives for social development. Africa Development. 2016; 41(4): 47-69.

[25] Gbeasor-Komlanvi FA, Zida-Compaore WI, Sadio AJ, et al. HIV testing uptake and prevalence among hospitalized older adults in Togo: A cross-sectional study. PLoS One. 2021; 16(2): e0246151.

[26] Kwabena-Adade JO. Home away from home: The emerging forms of aged Care in the Urban Centres of the Greater Accra region of Ghana.

[27] Wuaku DA, Esena RK, Aniteye P, Adomah-Afari A. Utilization of Healthcare Services by the Elderly Patients at Korle-Bu Teaching Hospital, Accra. Am Sci Res J Eng Technol Sci. 2021; 77(1): 48-62.

[28] Gaebel A, Keiser M. Challenges in the management of geriatric trauma: A case report. J Trauma Nurs. 2017; 24(4): 245-50.

[29] Kumlin M, Berg GV, Kvigne K, Hellesø R. Elderly patients with complex health problems in the care trajectory: a qualitative case study. BMC Health Serv Res. 2020; 20(1): 1-0.

[30] Nechba RB, Kadiri ME, Bennani-Ziatni M, Zeggwagh AA, Mesfioui A. Difficulty in managing polypharmacy in the elderly: case report and review of the literature. J Clin Gerontol Geriatr. 2015; 6(1): 30-3. 